\title{
Scoliosis with hyperkyphosis combines in $20 \%$ of cases with Scheuermann's disease, and is more frequent in males
}

\author{
S Atanasio ${ }^{1 *}$, S Donzelli ${ }^{1}$, F Zaina ${ }^{1}$, A Negrini', S Negrini ${ }^{2,3}$ \\ From 9th International Conference on Conservative Management of Spinal Deformities - SOSORT 2012 \\ Annual Meeting \\ Milan, Italy. 10-12 May 2012
}

\section{Background}

For most scoliosis cases, the etiology is uncertain. It's possible, however, that a certain number of idiopathic scoliosis cases could be classified by known vertebral spine pathologies. It's been described in the literature that idiopathic scoliosis is related to dorsal hypokyphosis, but the existence of scoliosis in which this doesn't happen has been proved. Scheuermann's $(\mathrm{SCH})$ disease, in addition to hyperkyphosis, sometimes presents also average severity scoliosis. We wondered in how many cases a $\mathrm{SCH}$ disease, with a prevailing lateral component, would cause important scoliosis in association with hyperkyphosis.

\section{Aim}

To verify the presence of vertebral alterations connected to Scheuermann's disease in scoliosis considered idiopathic.

\section{Methods}

Design: Cross-sectional study. Population: inclusion criteria was principal diagnosis of Idiopathic Scoliosis with a curve of at least $20^{\circ} \mathrm{Cobb}$; sum of the sagittal plane between C7 and L3 of $90 \mathrm{~mm}$. From a database of 2,432 patients affected by scoliosis greater than $20^{\circ}, 201$ subjects (49 male and 152 female) satisfied those conditions. All the patient's radiographs (769 overall) have been evaluated in order to identify the presence of the signs of Scheuermann disease in one vertebra at least.

\section{Results}

Scoliosis with combined increase of the curves on the sagittal plane is $8.3 \%$. In this subgroup, males are $24.4 \%$. Radiographic signs of Scheuermann's disease have been found in 45 patients (23.3\% of the 201 subjects under study). Among those, 14 were male (31.1\%) and 31 female. Comparing to the classification according to Lenke, 6 of them were of type 1,31 of type 3 , and 8 of type 5 .

\section{Conclusion}

Among IS with combined hyperkyphosis, the prevalence of the male sex is greater than what is reported for the common form of IS. According to our results, in a significant number of idiopathic scoliosis, alterations related to Scheuermann's disease have been reported in one or more vertebrae: in these cases the rate of males slightly increases. This could imply the exclusion of this subgroup from IS.

\section{Author details}

${ }^{1}$ ISICO (Italian Scientific Spine Institute), Milan, Italy. ${ }^{2}$ University of Brescia, Italy. ${ }^{3}$ RCCS Don Gnocchi Milan, Italy.

Published: 3 June 2013

\section{Reference}

1. Bradford DS: Juvenile Kyphosi. In Moe's Textbook of Scoliosis and Other Spinal Deformities.. 3 edition. Philadelphia: W.B. Saunders Company;Bradford DS, Lonstein JE, Ogilvie JW, R.B. W 1995:349-367.

doi:10.1186/1748-7161-8-S1-O3

Cite this article as: Atanasio et al:: Scoliosis with hyperkyphosis

combines in $20 \%$ of cases with Scheuermann's disease, and is more frequent in males. Scoliosis 2013 8(Suppl 1):O3.

'ISICO (Italian Scientific Spine Institute), Milan, Italy

Full list of author information is available at the end of the article

(c) 2013 Atanasio et al; licensee BioMed Central Ltd. This is an Open Access article distributed under the terms of the Creative 